\title{
Advances in necrotizing enterocolitis
}

\author{
Nelson Diniz de Oliveira, ${ }^{1}$ Milton Harumi Miyoshi ${ }^{2}$
}

\begin{abstract}
Objective: To evaluate recently reported findings on necrotizing enterocolitis, paying particular attention to pathogenesis, management and preventative strategies.

Data sources: The articles covered in this report consist of randomized and quasi-randomized trials, case control studies, meta-analyses and reviews published recently. Certain other articles were also included because of their utmost importance to the subject.

Results: Necrotizing enterocolitis remains a major cause of morbidity and mortality in preterm infants. Those who are born with intra-uterine-growth retardation are at a several-fold increased risk. Possible pathophysiologic processes beginning in utero and continuing after birth are discussed in this review. Other factors involved in the process are related to the role of arginine and the production of intestinal nitric oxide and the action of epidermal growth factor in the regulation of cell regeneration. Perforated necrotizing enterocolitis is a complex surgical problem; definitive evidence-based guidelines for the best approach are yet to be determined. After surgery, although residual small bowel length and the presence of the ileo-cecal valve remain important predictors of duration of parenteral nutrition in infants, other factors, such as the early use of breast milk or amino acid-based formula, may also play a role in intestinal re-adaptation. Prevention strategies have centered on feeding practices and emerging experiments such as amino acid supplementation, are also discussed.

Conclusion: Significant results in terms of mortality and morbidity will be achieved through better understanding of necrotizing enterocolitis pathogenesis and clinical and surgical management in addition to the employment of preventative strategies.
\end{abstract}

J Pediatr (Rio J). 2005;81(1 Suppl):S16-S22: Necrotizing enterocolitis, prematurity, short bowel syndrome.

\section{Introduction}

Necrotizing enterocolitis (NEC) is a clinicopathological syndrome characterized by progressive gastrointestinal and systemic signs and symptoms of varying intensity resulting from coagulation necrosis of the gastrointestinal tract, generally located in the terminal ileum, ascending colon and the proximal transverse colon. ${ }^{1}$ It affects premature babies with greater frequency, in particular those who are born with weights of less than $1,500 \mathrm{~g}$, and just 5 to $10 \%$ of classic cases of the disease affect full term babies. ${ }^{2-4}$ It is estimated that the disease affects between 5 and $15 \%$ of premature infants and around $7 \%$ of fullterm neonates

1. Professor, Escola Superior de Ciências da Saúde (SES). Coordinator of the Neonatology and Neonatal Intensive Care Unit, Hospital Santa Lúcia, Brasília, DF, Brazil.

2. Assistant professor of Neonatal Pediatrics, Department of Pediatrics, Universidade Federal de São Paulo (UNIFESP/EPM) and medical consultant of the Neonatal Intensive Care Unit, Hospital e Maternidade Santa Joana, São Paulo, SP, Brazil.

Suggested citation: de Oliveira ND, Miyoshi MH. Advances in necrotizing enterocolitis. J Pediatr (Rio J). 2005;81(1 Suppl):S16-S22. admitted to neonatal intensive care units. ${ }^{5}$ Recent observations have revealed an increase in the incidence of NEC. In the USA, the estimate is a figure of 6,000 cases annually. 6,7

In general the clinical manifestations occur during the first week of life, ${ }^{2,3,8}$ although some centers report later onset. ${ }^{9}$ This pattern is typically observed among premature infants when they are in a convalescent phase, recovering from the base disease. In full term newborns, however, manifestations generally occur during the first days of life. Symptoms have a wide variation in terms of presentation, from non-specific cases with mild abdominal distension, increased gastric residue, lethargy and thermal instability, to the most obvious cases with pronounced abdominal distension, enterorrhagia, signs of peritonitis, sepsis, septic shock and multiple organ failure. ${ }^{10-12}$ Staging of NEC based on clinical and radiological findings has proven useful in guiding treatment and for prognostic assessments. ${ }^{10,13}$ In daily practice it is only possible to define the final stage of severity of the disease from the second day of manifestation onwards. In cases where only mild systemic and abdominal 
findings are observed over the first 48 hours of the course of the disease it is unlikely that there will be a more serious outcome. ${ }^{10}$ However, it should be remembered that in practice the velocity with which clinical decline takes place can not be predicted.

Despite the achievements observed in perinatal care over the last decade, the prognosis of newborns with NEC has not improved. In fact, over recent years a tendency has been observed for the number of deaths from this condition to increase. ${ }^{14}$ The mortality rate is between 18 and $45 \%$, depending upon the degree of prematurity and the severity of infection. Furthermore, survivors present a great risk of developing stenosis of the affected segment and short bowel syndrome. $9,13-17$

While the exact cause is still considered an enigma, it is accepted that NEC results from an initial insult to the intestinal mucosa, resulting from the action of a variety of factors on an immature gastrointestinal system, followed by a series of inflammatory reactions in cascade, proliferation and bacterial invasion of the intestinal mucosa culminating in coagulation necrosis of the affected areas. This article aims to review the most recent aspects involved in the etiopathogenesis of NEC, exploring factors involved in better management and prevention of the condition.

\section{Etiopathogenesis}

\section{The role of intrauterine growth impairment, gastrointestinal immaturity and perinatal asphyxia}

It is still customary to state that babies born small for gestational age (SGA) exhibit accelerated organ maturation due to intrauterine stress and are therefore less prone to express the problems that result from prematurity when compared with premature newborns born at weights appropriate for gestational age. This statement, however, has been contested by a number of different recent observations which indicate that SGA preterms are a high risk group for developing NEC, when compared with those born at adequate weights. Thus, Zaw et al. ${ }^{7}$ analyzing the appearance of NEC among premature infants with gestational ages of less than 34 weeks, showed that intrauterine growth impairment increased the risk of the occurrence of the disease when they evaluated patients using neonatal growth standards (RR $2.47 ; 95 \%$ CI $1.21 ; 5.07$ ), although they did not observe the same effect when they used intrauterine growth curves for classification (RR 1.78; 95\% CI 0.93; 3.38). Similarly, Bernstein et al., analyzing the VermontOxford network's database for premature infants born at gestational ages between 25 and 30 weeks, found an increased occurrence of the disease among those that presented retarded growth (RR $1.27 ; 95 \%$ CI $1.05 ; 1.53) .{ }^{18}$ Hallstrom et al. ${ }^{19}$ studied newborn babies with gestational ages of less than 33 weeks and observed that growth impairment was a significant risk factor for developing the more severe forms of the disease (RR 4.55; 95\% CI 1.00; 19.5). More recently Garite et al. ${ }^{20}$ evaluated around 30,000 premature newborn babies over 5 years and observed that for the same weight, SGA babies had older gestational ages and therefore appeared to have better prognosis. However, when the children were matched for gestational age, the group with intrauterine growth impairment exhibited greater risk of death, of developing NEC, of oxygen dependency at 28 days of age and of presenting retinopathy of prematurity. It is believed that in situations where there is growth impairment, intrauterine hypoxia promotes a redistribution of cardiac output depriving the immature intestine of adequate oxygenation and thus contributing to the development of NEC. ${ }^{21}$ Doppler studies assessing blood flow showed a reduction in flow velocity through the superior mesenteric artery and celiac trunk of fetuses who progress with growth retardation. This alteration remains after birth, during the first week of life, leading some authors to believe that the greater postnatal mesenteric vascular resistance is programmed during intrauterine life. ${ }^{22}$ In an attempt at early identification of those newborns who had suffered form a state of chronic intrauterine asphyxia, and thus obtain a marker of risk of NEC, Mandel et al. retrospectively investigated 23 premature infants who had had the disease confirmed (Bell stage II). The authors observed that reticulocytosis was a statistically significant variable for the group with NEC when compared with the controls, suggesting that an elevated reticulocyte count may allow the definition of a subset of preterms at greater risk of developing the disease. 23

\section{The role of amino acids}

The adequate growth and development of the gastrointestinal tract and its ability to sustain a series of digestive and absorbent functions is dependent on an appropriate supply of a number of different nutrients. Arginine is an amino acid that can be synthesized by enterocytes and is a primary source of nitrogen for local nitric oxide production. ${ }^{24}$ Nitric oxide is a potent mediator that induces relaxation in vascular smooth muscle and, in this manner, regulates the basal tone of the arterioles, performing an important role in the control of blood flow to the intestinal mucosa. Studies of experimental models using ischemia, hypoxia, toxins or platelet activating factor to induce intestinal damage have shown that inhibiting nitric oxide synthesis is associated with increased tissue damage whereas if it is supplied exogenously the effect is attenuated. ${ }^{25-27}$ Some studies have demonstrated lower plasma levels of arginine and glutamine in premature newborn babies suffering from NEC than in babies without the disease. ${ }^{28,29}$ Di Lorenzo et al. showed that a continuous infusion of arginine attenuated intestinal injury in an experimental model. ${ }^{30}$ In a similar manner, Akisu et al. found that oral supplementation of arginine and carnitine (an amino acid with antioxidant properties) significantly reduced intestinal tissue damage in mice subjected to hypoxia followed by re-oxygenation. ${ }^{31}$ In a prospective, randomized and blind study of humans, Amin et al. analyzed the effect of supplementing with $1.5 \mathrm{mmol} / \mathrm{kg}$ per day of L-arginine premature infants with gestational ages of less than 32 weeks and birth weights below $1,250 \mathrm{~g} .{ }^{32}$ The authors observed that prophylactic arginine supplementation reduced the incidence of NEC at all 
stages ( 7 versus $27 \%$ ). Although further studies are needed to explore the true role of supplementation with amino acids like carnitine and arginine in the genesis of NEC, the fact that their administration can reduce the incidence of the disease is an exciting fact awakening great promise for future preventative actions.

\section{The role of epidermal growth factor}

Epidermal growth factor (EGF) belongs to a vast family of peptides (transforming growth factor-alpha, amphiregulin, heparin-binding EGF, epiregulin, betacellulinn and neuroregulin, among others) which provoke a variety of biological responses in the gastrointestinal tract, the majority of which involve regulation of cell replication and cell movement and survival. This family of peptides has an affinity for a specific receptor, the EGF receptor, which can be found distributed across the entire gastrointestinal tract of the fetus and neonate. ${ }^{24}$ The exact location of these receptors in the small intestine is in the baso-lateral compartment of epidermal cells and the apical membrane of the villous epithelium. The earliest evidence relating EGF and NEC was found by Sullivan et al. These authors described the case of a child of 8 months with a case of intestinal necrosis similar to NEC and for whom continuous EGF administration over a period of 4 days led to recovery. 33 Soon Scott et al. had observed a high rate of urinary excretion of EGF in newborns with NEC. The authors speculated that this fact could be the result of greater EGF absorption by the injured intestine. ${ }^{34}$ Other studies point to the association between low levels of EGF in saliva and serum and NEC, 35,36 with some authors raising the hypothesis that EGF administration could be active in both prevention and treatment of the disease. ${ }^{36}$ Wong $\&$ Wright summarize current knowledge on the role of EGF in the growth and development of the gastrointestinal tract, pointing out that intra-luminal or parenteral administration could be a powerful weapon for protection and regeneration of intestinal cells. ${ }^{37}$

\section{Clinical and surgical management Surgical approach}

Considered the most common surgical emergency during the neonatal period, the operative approach to NEC still provokes doubts, whether with respect of the best time to intervene or the best technique to use because of the different stages of the disease and the great variability in weight and gestational age of the patients affected.

In clinical practice, all patients presenting with intestinal perforation are potential candidates for surgical treatment. The radiological finding most often associated with perforation of intestinal loops is the presence of pneumoperitoneum observed in antero-posterior x-rays of the abdomen or, preferably in left lateral decubitus with horizontal rays. However, Kosloske studied prospectively a cohort of 147 children, observing that pneumoperitoneum, as a sign of intestinal perforation, was present in just $48 \%$ of cases, although specificity was $100 \%$. Other findings considered diagnostic of perforation were the presence of liquid with a fecal or bilious appearance or the detection of germs with Gram's staining in material obtained by paracentesis. Relative indications for surgical intervention were the presence of air in the portal system, intestinal loops in a fixed position over serial $x$-rays of the abdomen, erythema of the abdominal wall or a palpable mass in the abdomen. ${ }^{38}$ In daily practice, however, the decision on the need for intervention and the most suitable time is, in the majority of cases, individualized, being based on the evolving analysis of clinical, laboratory and $x$-ray findings. Furthermore, it should be borne in mind that these patients very often are in a critical state, making the decision more difficult. The decision should, preferably, be taken in conjunction by the multidisciplinary team of surgeon, anesthetist and neonatologist.

The two most common procedures are simple peritoneal drainage and explorative laparotomy with resection of the affected segment followed by primary anastomosis or enterostomy. Leaving to one side individual preferences for laparotomies with resection or simple peritoneal drainage, a tendency is observed in the relevant literature to indicate the latter procedure for patients of lower weight or younger gestational ages and suffering from a greater number of aggravating factors. Erlich et al., reviewing the surgical procedures performed on 70 newborn babies with birth weights of less than $1,000 \mathrm{~g}$ who had developed NEC, observed a survival rate of $63 \%$ among children who underwent peritoneal drainage and $75 \%$ among those subjected to laparotomy. However, the patients who underwent peritoneal drainage presented a greatly increased number of complications. Using a regression analysis the authors concluded that the choice of surgical operation had not influenced the final outcome. ${ }^{39}$ Recently, Moss et al. performed a meta-analysis of studies that had used both procedures to treat children with NEC. The analysis covered 475 patients and did not reveal statistically significant differences between laparotomy and peritoneal drainage in terms of mortality. It did, however, call attention to a significant selection bias since the average weight of the children subjected to laparotomy was $1,615 \mathrm{~g}$ while that of the children who underwent drainage was $931 \mathrm{~g}(\mathrm{p}=0.0004)$. The authors therefore concluded that, using uncontrolled data, there is no evidence for concluding whether laparotomy or peritoneal drainage is the better surgical approach. ${ }^{40}$ The results of that study formed the basis for a multicenter randomized clinical trial, currently in progress, that unites 13 North-American institutions under the supervision of the National Institutes of Health. ${ }^{41}$

\section{Parenteral and enteral nutrition}

Short bowel syndrome is one of the most significant complications secondary to NEC in which there was a need for extensive intestinal resection. It is known that after resection the remaining section of the intestine undergoes a process of adaptation characterized by hyperplasia of the mucosa, increase in villous extension, deepening of the crypts and dilation of the intestine. ${ }^{42,43}$ The use of parenteral nutrition to meet nutritional requirements is an important tool to enable intestinal function to be recovered, permitting 
enteral nutrition, sequentially instituted, to gradually substitute the parenteral modality. Nevertheless, the clinical course of patients with short bowel syndrome is very often unpredictable, meaning that parenteral nutrition can be used for prolonged periods and, in certain situations for indeterminable periods as a result of the intestine failing to readapt to full enteral nutrition. This, in turn increases the risk of complications such as infectious processes, cholestasis, inadequate bone mineralization and death. Andorsky et al., aiming to analyze the factors that influence the duration of and dependence on parenteral nutrition, retrospectively studied 30 children with short bowel syndrome, around half of whom had the syndrome as a result of NEC. The definition of short bowel syndrome was restricted to neonates who had undergone intestinal resection and/or intestinal malformation and required at least 90 days' parenteral nutrition. Enteral feeding was instituted with small quantities of maternal breastmilk or amino acid formula (Neocate, SHS Inc), which were gradually increased in accordance with patient tolerance. The authors observed that the presence of an intestinal segment greater than $83 \mathrm{~cm}( \pm 67 \mathrm{~cm})(r=-0.475)$ and enteral feeding with maternal milk $(r=-0.821)$ or amino acid formula $(r=-0.793)$ were associated with shorter period of parenteral nutrition use. Furthermore, they noted that the use of maternal breastmilk was the factor that showed the greatest correlation with the period of parenteral nutrition. 44 In this series there was no relation between maintenance of the ileocecal valve and the duration of parenteral nutrition, which some other studies have found to be significant. 45,46 Early institution of enteral feeding appears to exercise a series of benefits on these patients' recovery, in particular when maternal breastmilk was used as a result of the immunological factors and EGF it contains. ${ }^{24,44}$ Thus, Bohnhorst et al. studied the postoperative progress of children with NEC at Bell stages II and III who had been subjected to intestinal resection taking into consideration the differences resulting from the time of reintroduction of enteral feeding with formulae. ${ }^{47}$ Group 1 , composed of 26 children, were reintroduced to feeding in an average of 4 days (3-14 days) and in group 2, composed of 18 children, the average time before reintroducing feeding was 10 days (8-22 days). The early group exhibited a shorter period before achieving total enteral feeding (10 days versus 19 days, $p<0.001)$, shorter period of central venous access (13.5 days versus 26 days, $p<0.1$ ), lower percentage of catheter-related sepsis ( $18 \%$ versus $29 \%, \mathrm{p}<0.1)$ and a shorter length of hospital stay (63 days versus 69 days, $\mathrm{p}<0.5)$. More recently, Quirós-Tejeira et al., in an uncontrolled study, retrospectively analyzed data from 78 children with short bowel syndrome who had required parenteral nutrition for a period of more than 3 months. 48 The authors observed that the best survival rate was associated with a remaining small intestine segment of more than $38 \mathrm{~cm}$, an intact ileocecal valve, intestinal reconstruction after stomas and primary anastomosis. The use of parenteral nutrition, early onset and persistent cholestasic jaundice, and also a small intestine remnant smaller than $15 \mathrm{~cm}$, were associated with increased mortality.
There was a smaller chance of intestinal readaptation if the extension of remaining small intestine was less than $15 \mathrm{~cm}$, if the ileocecal valve or colon were resectioned and if primary anastomosis could not be performed. The survival rate of the sample analyzed was $73 \%$, with $77 \%$ of the survivors achieved intestinal readaptation.

\section{Preventive measures}

Over the years a number of different strategies have been developed to prevent the appearance of NEC. However, to date the majority of these measures are based on clinical observation and some experimental data.

\section{Antenatal corticoid therapy}

Since premature birth is the most important risk factor for developing NEC, the possibility that intestinal maturation could be induced medicinally with antenatal corticosteroid has been investigated. In a randomized multicenter study, Bauer et al. observed a significant reduction in the incidence of NEC among children whose mothers had received corticosteroid during the prenatal period. ${ }^{49}$ The same result was presented by Halac et al. in a controlled trial. ${ }^{50} \mathrm{Smith}$ et al. retrospectively analyzed the progress of children whose mothers had received one course, multiple courses or no courses of antenatal corticosteroid. The authors observed that those who had received one course of medication presented a lower incidence of NEC. ${ }^{51}$ Other experiments, however, have not demonstrated the same results. Kamisuka et al., analyzing premature infants born at gestational ages of less than 35 weeks and with birth weights between 1,250 and 2,500 g, observed an incidence of NEC that was twice as frequent among the children whose mothers had received antenatal corticosteroid. 52 Similarly, Guthrie et al., analyzing the databases of 98 North-American neonatal intensive care units, observed that exposure to antenatal steroids increased the risk of the appearance of NEC. 53 Despite these findings, the use of antenatal steroids is currently defined as an important measure for reducing morbidity and mortality resulting from pulmonary immaturity and prematurity. Due to the great stimulus towards using antenatal corticosteroid nowadays, over the next few years more and more premature babies will be exposed to the medication before birth and it is possible that the relation between the use of corticosteroid and incidence of NEC will become clearer.

\section{Early closing of patent ductus arteriosus}

It is known that the presence of patent ductus arteriosus (PDA) promotes the diversion of blood volume to the pulmonary arteries in the diastolic phase, which leads to the reduction of splenic perfusion, thus increasing the risk of NEC. ${ }^{54}$ In a controlled and randomized trial with premature infants with birth weights less than or equal to $1,000 \mathrm{~g}$, Cassady et al. observed that early surgical ligature of the ductus arteriosus reduces the chance of 
NEC developing. ${ }^{55}$ From the eighties onwards indomethacin began to be used prophylactically for closing ductus arteriosus and prevention of intracranial hemorrhage. The research that followed showed an effective action in reducing these situations although side effects such as reduced splenic blood flow put a check on the universal recommendation for their usage. 56 Thus, Grosfeld et al. reported an increase in the incidence of NEC and intestinal perforation in children who received indomethacin for PDA treatment. ${ }^{57}$ In the same area of research, Pezzati et al. ${ }^{58}$ studied the effect of indomethacin and ibuprofen on blood flow through the superior mesenteric and renal arteries, in children with PDA. The authors observed that indomethacin caused a significant reduction of blood flow through these vessels after 30 minutes. Also of interest was that even after 120 minutes the flow intensity had not returned to the base values observed before treatment. The same situation was not observed with the use of ibuprofen. On the other hand, in a retrospective study O'Donovan et al. ${ }^{59}$ observed that the use of indomethacin for PDA treatment was not associated with an increased risk for the appearance of NEC. More recently, Cooke et al., in a review analysis for the Cochrane Library, concluded that there was no evidence that the use of indomethacin was associated with an increased risk of NEC. 60

\section{Enteral antibiotic therapy and immunoglobulins}

Based on the theory that bacterial colonization and subsequent proliferation on the surface of the damaged intestinal mucosa contributes to the appearance of NEC, a number of different studies, with conflicting results, used antibiotics by enteral route (aminoglycosides in general) to prevent the condition. ${ }^{61-63}$ In a prospective, randomized and double-blind study, Siu et al. evaluated vancomycin for NEC prophylaxis. ${ }^{64}$ The authors observed a reduction in the condition in the treatment group (13\% versus $27 \%$ ). In a review study for the Cochrane Library, Bury \& Tudehope evaluated five studies that used antibiotics via enteral route for NEC prophylaxis in low birth weight premature infants. The collective analysis of these studies suggests that antibiotic therapy by enteral route significantly reduces both the incidence and related deaths of NEC. Overall, they concluded that because of the pronounced risk of encouraging resistant bacterial strains, the existing evidence did not justify the administration of antibiotics by enteral route for NEC prevention. 65

Since premature infants have low levels of immunoglobulins, particularly secretory IgA, a series of research projects have been performed to observe the role of the prophylactic use of oral immunoglobulins in the prevention of NEC. In a randomized clinical trial, Eibl et al. evaluated the efficacy of an oral preparation of immunoglobulins (73\% - IgA and $26 \%$ - IgG) for preventing NEC in children who had not received maternal milk. 66 The authors observed a significant reduction in cases of NEC in the treatment group ( $0 \%$ versus $6.6 \%$ ). In a similar manner, Rubaltelli et al. noted a significant reduction in NEC cases among children fed exclusively on formula after the administration of an oral immunoglobulin preparation containing $90 \%$ of IgG. ${ }^{67}$ Nevertheless, Foster \& Cole performed a meta-analysis for the Cochrane Library, concluding that the currently existing evidence does not yet support the use of oral immunoglobulin in clinical practice for NEC prevention. 68 Similarly, the use of intravenous immunoglobulin, despite having evidence in its favor in terms of reducing nosocomial infections, did not demonstrate beneficial effects for the prevention of NEC. 69

\section{Amino acid supplementation}

It is known that the classic histopathological finding in NEC is coagulation necrosis, which presupposes the previous action of local or systemic ischemic events. In the knowledge that such phenomena might be involved in the pathogenesis of NEC, ${ }^{70,71}$ the role of the vasodilatory action of nitric oxide has acquired special importance. The nitric oxide is produced during the enzymatic conversion of L-arginine into under the synthase action of nitric oxide. As has been explored above, supplementation with exogenous arginine appears to demonstrate elements that are promising for the prevention of NEC. $30-32$

\section{Maternal breastmilk}

Epidemiological studies and experimental models have shown that the use of maternal milk for feeding premature infants reduce the incidence of NEC. ${ }^{72,73}$ Thus, studies show that preterm newborns fed exclusively with formula have a risk from six to 10 times greater of developing the condition when compared with children who received human milk. ${ }^{74}$ It is known that human milk contains a multitude of factors, such as immunoglobulins, erythropoietin, interleukin-10, EGF and acetylhydrolase, among others, that act to prevent NEC appearing. ${ }^{75}$ The presence of platelet activation factor (PAF), for example, has been implicated in the etiopathogenesis of NEC. ${ }^{76}$ Elevated concentrations of PAF have been found in newborn babies with NEC, while levels of the enzyme that provokes its hydrolysis (acetylhydrolase) were reduced. ${ }^{77}$ Human milk, and not bovine milk, is an important source of enzymes that lead to PAF hydrolysis. Another important datum is that human milk contains elevated levels of EGF, which cannot be found in commercial formulae. ${ }^{75}$

Recently McGuire \& Anthony, ${ }^{78}$ in a systematic review, analyzed four randomized or semi-randomized studies that compared the effect of banked human milk compared with formula on the appearance of NEC in premature infants born at weights of less than $2,500 \mathrm{~g}$. The metaanalysis showed that those children who received human milk presented a four times smaller risk of developing Bell stage II NEC. The authors comment that although pasteurized human milk has a lower protein content than a baby's own mother's milk, the presence of anti-infectious and immunological factors and EGF offer children protection in contrast with formulae which only present nutritional components. 


\section{Pre and probiotics}

Probiotics are live microorganisms offered as nutritional supplements (for example bifidobacterium), which act within the intestine of the host organism regulating the local bacterial flora. This being so, they act to improve gastrointestinal permeability, increasing mucosal resistance against bacterial penetration. Prebiotics, for example, are indigestible nutritional ingredients (for example oligofructose), which selectively stimulate the growth of benign bacterial species present in the colon, such as lactobacillus and bifidobacterium. To date, the evidence on the role of pre and probiotics in the prevention of NEC is based on reports of experiments with historical controls and on experimental models. Further studies are necessary which evaluate the true role of these products in a controlled manner, but they appear to be a promising weapon in the management of NEC. ${ }^{73}$

\section{Conclusions}

Although NEC remains one of the major challenges in neonatology, much knowledge has been accrued explaining its etiopathogenesis and opening fresh eyes to its management and prevention. The role of amino acids such as arginine and carnitine, the importance of EGF, the action of enzymes that provoke hydrolysis of platelet activation factor and the role of "fetal programming" caused by retarded intrauterine growth, are some of the pillars that will certainly have an influence, over the short term, on new approaches to the management of newborn babies suffering from NEC. Special attention has also been seen in the surgical approach, where more criteria-based techniques are being sought which are capable of affording better results over the long term, particularly with respect of the management of extremely low weight premature infants and the short bowel syndrome. Nowadays, the knowledge of the importance of the role of maternal breastmilk in the prevention and treatment of NEC is ever more firmly based. Therefore, the implementation of measures stimulating its use is a determinant marker of better results.

\section{References}

1. Israel EJ. Neonatal necrotizing enterocolitis, a disease of the immature intestinal mucosa barrier. Acta Paediatr Suppl. 1994;396:27-32.

2. Kliegman RM, Fanaroff AA. Neonatal necrotizing enterocolitis: a nine year experience: epidemiology and uncommon observations. Am J Dis Child. 1981;135:603-10.

3. Gamarra E, Helardot P, Morriete G. Necrotizing enterocolitis in full-term neonates. Biol Neonate. 1983;44:185-8.

4. Wilson R, del Portillo M, Schimidt E. Risk factors for necrotizing enterocolitis in infants weighing more than $2000 \mathrm{~g}$ at birth: a case control study. Pediatrics. 1983;71:19-25.

5. Kafetzis DA, Skevaki C, Costalos C. Neonatal necrotizing enterocolitis: an overview. Curr Opin Infect Dis. 2003;16:349-55.

6. Lemons JA, Bauer CR, Oh W, Korones SB, Papile LA, Stoll BJ, et al. Very low birth weight outcomes of National Institute of Child Health and Human Development neonatal research network, January 1995 through December 1996. NICHD Neonatal Research Network. Pediatrics. 2001;107:E1-8.
7. Zaw W, Gagnon R, da Silva O. The risk of adverse neonatal outcome among preterm small for gestational age infants according to neonatal versus fetal growth standards. Pediatrics. 2003;111:1273-7.

8. Dykes EH, Gilmour WH, Azmy AF. Prediction of outcome following necrotizing enterocolitis in a neonatal surgical unit. J Pediatr Surg. 1985;20:2-6.

9. Vieira MT, Lopes JM. Fatores associados à enterocolite necrosante. J Pediatr (Rio J). 2003;79:159-64.

10. Walsh MC, Kliegman RM. Necrotizing enterocolitis: treatment based on staging criteria. Pediatr Clin North Am. 1986;33:179-84.

11. Leonidas JC, Hall RT. Neonatal pneumatosis coli: a mild form of neonatal necrotizing enterocolitis. J Pediatr. 1976;89:456-9.

12. Barnard JA, Cotton RB, Lutin W. Necrotizing enterocolitis. Variables associated with severity of disease. Am J Dis Child. 1985; 139:375-80.

13. Buch NA, Ahmad SM, Ali SW, Hassan HM. An epidemiological study of neonatal necrotizing enterocolitis. Saudi Med J. 2001;22:231-7.

14. Schettini ST, Miyoshi MH. Enterocolite necrosante neonatal. Pediatria Moderna. 1999;35:145-58.

15. Stevenson DK, Kerner JA, Malachowski N, Sunshine P. Late morbidity among survivors of necrotizing enterocolitis. Pediatrics. $1980 ; 66: 925-7$.

16. Kliegman R, Fanaroff A. Neonatal necrotizing enterocolitis. N Engl J Med. 1984;310:1093-103.

17. $\mathrm{Ng} \mathrm{S}$. Necrotizing enterocolitis in the full-term neonates. J Paediatr Child Health. 2001;37:1-4.

18. Bernstein IM, Horbar JD, Badger GJ, Ohlsson A, Golan A. Morbidity and mortality among very-low-birth-weight neonates with intrauterine growth restriction: the Vermont Oxford Network. Am J Obstet Gynecol. 2000;182:198-206.

19. Hallstrom M, Koivisto AM, Janas M, Tammela O. Frequency of risk factors for necrotizing enterocolitis in infants born before 33 weeks of gestation. Acta Paediatr. 2003;92:111-13.

20. Garite TJ, Clark R, Thorp JA. Intrauterine growth restriction increases morbidity and mortality among premature neonates. Am J Obstet Gynecol. 2004;191:481-7.

21. McMillen IC, Adams MB, Ross JT, Coulter CL, Simonetta G, Owens $\mathrm{JA}$, et al. Fetal growth restriction: adaptations and consequences. Reproduction. 2001;122:195-204.

22. Kempley ST, Gamsu HR, Vyas S, Nicolaides K. Effects of intrauterine growth retardation on postnatal visceral and cerebral blood flow velocity. Arch Dis Child. 1991;66:1115-18.

23. Mandel D, Lubetzky R, Mimouni FB, Cohen S, Littner $Y$, Deutsch $V$, et al. Nucleated red blood cells in preterm infants who have necrotizing enterocolitis. J Pediatr. 2004;144:653-5.

24. Burrin DG, Stoll B. Key nutrients and growth factors for neonatal gastrointestinal tract. Clin Perinatol. 2002;29:65-96.

25. Payne D, Kubes P. Nitric oxide donors reduce the rise in reperfusion-induced intestinal mucosal permeability. Am J Physiol. 1993;265:G189-95.

26. Caplan MS, Hedlund E, Hill N, MacKendrick W. The role of endogenous nitric oxide and platelet activating factor in hypoxiainduced intestinal injury in rats. Gastroenterol. 1993;28:149-54.

27. Kubes $P$. Ischemia-reperfusion in feline small intestine: a role for nitric oxide. Am J Physiol. 1993;264:G143-9.

28. Zamora SA, Amin HJ, McMillan DD, Kubes P, Fick GH, Butzner $J D$, et al. Plasma L-arginine concentrations in premature infants with necrotizing enterocolitis. J Pediatr. 1997;131:226-32.

29. Becker RM, Wu G, Galanko JA, Chen W, Maynor AR, Bose CL, et al. Reduced serum amino acid concentrations in infants with necrotizing enterocolitis. J Pediatr. 2000;137:785-93.

30. Di Lorenzo M, Bass J, Krantis A. Use of L-arginine in the treatment of experimental necrotizing enterocolitis. J Pediatr Surg. 1995;30:235-40.

31. Akisu M, Ozmen D, Baka M, Habif S, Yalaz M, Arslanoglu S, et al. Protective effect of dietary supplementation with L-arginine and L-carnitine on hypoxia/reoxygenation-induced necrotizing enterocolitis in young mice. Biol Neonate. 2002;81:260-5.

32. Amin HJ, Zamora SA, McMillan DD, Fick GH, Butzner JD, Parsons $H G$, et al. Arginine supplementation prevents necrotizing enterocolitis in premature infant. J Pediatr. 2002;140:425-31.

33. Sullivan PB, Brueton MJ, Tabar ZB, Goodlad RA, Lee CY, Wright NA. Epidermal growth factor in necrotizing enteritis. Lancet. $1991 ; 338: 53-4$.

34. Scott SM, Rogers C, Angelus P, Backstrom C. Effect of necrotizing enterocolitis on urinary epidermal growth factor levels. Am J Dis Chil. 1991;145:804-7. 
35. Helmrath MA, Shin CE, Fox JW, Erwin CR, Warner BW. Epidermal growth factor in saliva and serum of infants with necrotizing enterocolitis. Lancet. 1998;351:266-7.

36. Shin CE, Falcone Jr RA, Stuart L, Erwin CR, Warner BW. Diminished epidermal growth factor levels in infants with necrotizing enterocolitis. J Pediatr Surg. 2000;35:173-6.

37. Wong W, Wright NA. Epidermal growth factor, epidermal growth factor receptors, intestinal growth and adaptation. J Parenter Enteral Nutr. 1999;23:S83-8.

38. Kosloske AM. Indications for operation in necrotizing enterocolitis revisited. J Pediatr Surg. 1994;29:663-6.

39. Erlich PF, Sato TT, Short BL, Hartman GE. Outcome of perforated necrotizing enterocolitis in the very-low-birth weight neonate may be independent of the type of surgical treatment. Am Surg. 2001;67:752-6.

40. Moss RL, Dimmitt RA, Henry MC, Geraghty N, Efron B. A metaanalysis of peritoneal drainage versus laparotomy for perforated necrotizing enterocolitis. J Pediatr Surg. 2001;36:1210-13.

41. Moss RL. A randomized trial of primary drainage versus laparotomy and bowel resection for treatment of perforated necrotizing enterocolitis in premature infants. R01 HD 3846201A1, Bethesda (MD): NIH/NICHD; 2004.

42. Porus R. Epithelial hyperplasia following massive bowel resection in man. Gastroenterol. 1965;48:753-7.

43. Williamson RC. Intestinal adaptation (second of two parts). Mechanisms of control. N Engl J Med. 1978;298:1444-50.

44. Andorsky DJ, Lund DP, Lillehei CW, Jaksic T, DiCanzio J, Richardson DS, et al. Nutritional and other postoperative management of neonates with short bowel syndrome correlates with clinical outcomes. J Pediatr. 2001;139:27-33.

45. Goulet OJ, Revillon Y, Jan D, De Potter S, Maurage C, LortatJacob S, et al. Neonatal short bowel syndrome. J Pediatr. 1991;119:18-23.

46. Mayr JM, Schober PH, Weissensteiner U, Hollwarth ME. Morbidity and mortality of the short-bowel syndrome. Eur J Pediatr Surg. 1999; 9:231-5.

47. Bohnhorst B, Muller S, Dordelmann M, Peter CS, Petersen C, Poets CF. Early feeding after necrotizing enterocolitis in preterm infants. J Pediatr. 2003;143:484-7.

48. Quirós-Tejeira RE, Ament ME, Reyen L, Herzog F, Merjanian M, Olivares-Serrano $N$, et al. Long-term parenteral nutritional support and intestinal adaptation in children with short bowel syndrome: a 25 year experience. J Pediatr. 2004;145:157-63.

49. Bauer Cr, Morrison JC, Poole WK, Korones SB, Boehm JJ, Rigatto $\mathrm{H}$, et al. A decreased incidence of necrotizing enterocolitis after prenatal glucocorticoid therapy. Pediatrics. 1984;73:682-8.

50. Halac E, Halac J, Begue EF, Casanas JM, Indiveri DR, Petit JF, et al. Prenatal and postnatal corticosteroid therapy to prevent neonatal necrotizing enterocolitis: a controlled trial. J Pediatr. 1990;117:132-8.

51. Smith LM, Qureshi N Chao CR. Effects of single and multiple courses of antenatal glucocorticoids in preterm newborns less 30 weeks gestation. J Matern Fetal Med. 2000;9:131-5.

52. Kamisuka MD, Horton HK, Williams MA. The incidence of necrotizing enterocolitis after introducing standardized feeding schedules for infants between 1250 and $2500 \mathrm{~g}$ and less 35 weeks of gestation. Pediatrics. 2000;105:379-84.

53. Guthrie SO, Gordon PV, Thomas V, Thorp JA, Peabody J, Clark $\mathrm{RH}$. Necrotizing enterocolitis among neonates in the United States. J Perinatol. 2003;23:278-85.

54. Ryder RW, Shelton JD, Guinan ME. Necrotizing enterocolitis: a prospective multicenter investigation. Am J Epidemiol. 1980;112:113-23.

55. Cassady G, Crouse DT, Kirklin JW, Strange MJ, Joiner CH, Godoi $\mathrm{G}$, et al. A randomized controlled trial of very early prophylatic ligation of the ductus arteriosus in babies who weighed $1000 \mathrm{~g}$ or less at birth. N Engl J Med. 1989;320:1511-16.

56. Fowlie PW, Davis PG. Prophylactic indomethacin for preterm infants: a systematic review and meta-analysis. Arch Dis Child Fetal Neonatal Ed. 2003;88:F464-6.

57. Grosfeld JL, Chaet M, Molinari F, Engle W, Engum SA, West KW, et al. Increased risk of necrotizing enterocolitis in premature infants with patent ductus arteriosus treated with indomethacin. Ann Surg. 1996;224:350-5.

58. Pezzati M, Vangi V, Biagiotti R, Bertini G, Cianciulli D, Rubaltelli F. Effects of indomethacin and ibuprofen on mesenteric and renal blood flow in preterm infants with patent ductus arteriosus. J Pediatr. 1999;135:733-8.
59. O'Donovan DJ, Baetiong A, Adams K, Chen A, Smith EO, Adams $\mathrm{JM}$, et al. Necrotizing enterocolitis and gastrointestinal complications after indomethacin therapy and surgical ligation in premature infants with patent ductus arteriosus. J Perinatol. 2003;23:286-90.

60. Cooke $L$, Steer $P$, Woodgate $P$. Indomethacin for asymptomatic patent ductus arteriosus in preterm infants. Cochrane Database Syst Rev. 2003;(2):CD003745.

61. Egan EA, Mantilla G, Nelson RM, Eitzman DV. A prospective controlled trial of oral kanamycin in the prevention of neonatal necrotizing enterocolitis. J Pediatr. 1976;89:467-70.

62. Boyle R, Nelson JS, Stonestreet BS, Peter G, Oh W. Alterations in stool flora resulting from oral kanamycin prophylaxis of necrotizing enterocolitis. J Pediatr. 1978;93:857-61.

63. Rowley MP, Dahlenburg GW. Gentamicin prophylaxis of neonatal necrotizing enterocolitis. Lancet. 1978;2:532.

64. Siu YK, Ng PC, Fung SC, Lee CH, Wong MY, Fok YF, et al. Double blind, randomized, placebo controlled study of oral vancomycin in prevention of necrotizing enterocolitis in preterm, very low birthweight infants. Arch Dis Child Fetal Neonatal Ed. 1998;79:F105-9.

65. Bury RG, Tudehope D. Enteral antibiotics for preventing necrotizing enterocolitis in low birthweight or preterm infants. Cochrane Database Syst Rev. 2001;(1):CD000405.

66. Eibl MM, Wolf HM, Furnkranz H, Rosenkranz A. Prevention of necrotizing enterocolitis in low birth-weight infants by IgA-IgG feeding. N Engl J Med. 1988;319:1-7.

67. Rubaltelli FF, Benini F, Sala M. Prevention of necrotizing enterocolitis in neonates at risk by oral administration of monomeric IgG. Dev Pharmacol Ther. 1991;17:138-43.

68. Foster J, Cole M. Oral immunoglobulin for preventing necrotizing enterocolitis in preterm and low birthweight neonates. Cochrane Database Syst Rev. 2004;(1):CD001816.

69. OhIsson A, Lacy JB. Intravenous immunoglobulin for preventing infection in preterm and/or low birthweight infants. Cochrane Database Syst Rev. 2004;(1):CD000361.

70. Crissing KD. Regulation of hemodynamics and oxygenation in developing intestine: insight into the pathogenesis of necrotizing enterocolitis. Acta Paediatr Suppl. 1994;396:8-10.

71. Nowicki P. Intestinal ischemia and necrotizing enterocolitis. J Pediatr. 1990;117:S14-19.

72. Barlow B, Santulli TV, Heird WC, Pitt J, Blanc WA, Schullinger JN. An experimental study of acute neonatal enterocolitis: the importance of breast milk. J Pediatr Surg. 1974;9:587-95.

73. Schanler RJ, Shulman RJ, Lau C. Feeding strategies for premature infants: beneficial outcomes of feeding fortified human milk versus preterm formula. Pediatrics. 1999;103:1150-7.

74. Lucas A, Cole TJ. Breast milk and neonatal necrotizing enterocolitis. Lancet. 1990;336:1519-23.

75. Reber K, Nankervis CA. Necrotizing enterocolitis: preventive strategies. Clin Perinatol. 2004;31:157-67.

76. Caplan MS, Lickerman M, Adler L, Dietsch G, Yu A. The role of recombinant platelet-activating factor acethylhydrolase in a neonatal rat model of necrotizing enterocolitis. Pediatr Res. 1997;42:779-83.

77. Caplan MS, Sun XM, Hseuh W, Hageman JR. Role of platelet activating factor and tumor necrosis factor-alpha in neonatal necrotizing enterocolitis. J Pediatr. 1990;116:960-4.

78. McGuire W, Anthony MY. Donor human milk versus formula for preventing necrotizing enterocolitis in preterm infants: systematic review. Arch Dis Child Fetal Neonatal Ed. 2003;88:F11-14.

Correspondence:

Nelson Diniz de Oliveira

SHIS QL 22, conjunto 6, casa 14

CEP 71650-265 - Brasília, DF

Brazil

Phone: +55 (61) 366.4125

Fax: +55 (61) 245.3531

E-mail: nelson.diniz@uol.com.br 